\title{
Windows to early childhood mathematics teacher education
}

\author{
Pessia Tsamir • Dina Tirosh $\cdot$ Esther Levenson
}

Published online: 18 February 2011

(C) Springer Science+Business Media B.V. 2011

This special issue comes at a time when the issue of early childhood mathematics has come to the fore. At a recent 2009 Conference of European Research in Mathematics Education, a new working group in Early Years Mathematics was established in response to increased calls for research regarding mathematics learning and mathematics teacher education in the early years (ages 3-8). A joint position paper published in the United States by the National Association for the Education of Young Children (NAEYC) and the National Council for Teachers of Mathematics (NCTM) stated that "high quality, challenging, and accessible mathematics education for 3-6 year old children is a vital foundation for future mathematics learning" (National Association for the Education of Young Children and National Council of Teachers of Mathematics 2002, p.1). Further evidence of concern for early childhood mathematics may be seen in the rise of national curricula in various countries which now make specific and sometimes mandatory recommendations for including mathematics as part of the preschool program. For example, in Israel, the National Mathematics Preschool Curriculum (Israel national mathematics preschool curriculum (INMPC) 2008) is mandatory and contains specific guidelines and aims for children from 3 to 6 years. A clear indication of the growing awareness of the importance of early childhood mathematics is the vast increase in the number of articles that are devoted to early childhood mathematics in the research literature. The inclusion of a specific chapter in which the current research on early childhood mathematics learning is summarized, in a handbook of research on mathematics teaching and learning for the first time, is a clear sign of the growing attention to this domain (Clements and Sarama 2007).

One may wonder about the recent, growing attention to early childhood mathematics. Evidently, there are institutional, economic, and equity issues that support this significant increment (e.g., a world-wide increase in the numbers of children attending early-care

P. Tsamir · D. Tirosh · E. Levenson $(\bowtie)$

School of Education, Tel Aviv University, Ramat Aviv, 69978 Tel Aviv, Israel

e-mail: Levenso@post.tau.ac.il

P. Tsamir

e-mail: Pessia@post.tau.ac.il

D. Tirosh

e-mail: Dina@post.tau.ac.il 
institutions and consequently, the development of related, educational programs). Furthermore, there are recent indications that early knowledge of mathematics is a predictor of later school success (Jimerson et al. 1999) and that it is a stronger predictor than tests of intelligence or memory abilities (Krajewski 2005).

One may also wonder about the mathematical knowledge needed for teaching mathematics in early childhood. Generally, there is wide agreement that teachers play a critical role in developing a solid, mathematical foundation for their students (e.g., Shulman 1986; Ball et al. 2008). Early childhood mathematics teachers are not an exception. In fact, research suggests that the most critical feature of a high-quality educational environment in preschools is a knowledgeable adult (e.g., Bowman et al. 2001). However, few studies focus on various aspects of early childhood mathematics teacher education (e.g., knowledge of relevant domains, successful teacher education, and professional development programs) (see, for instance, Sarama and DiBiase 2004). A clear indication of this deficiency is that a search of the twelve already published volumes of Journal of Mathematics Teacher Education reveals not one article that directly addresses preschool mathematics teacher education.

Mathematics teacher education programs for all ages should be based on solid research findings. In light of the lack of research related to the mathematics education of early childhood teachers in the current research corpus and in light of the importance of this domain, we felt a need to propose this special issue. We hope that this special issue will act as a catalyst, encouraging additional research on the many fascinating aspects of early childhood mathematics teacher education. This special issue could be viewed, in a way, as a stepping stone, a first attempt to build a research-based body of knowledge pertaining to the mathematics education of early childhood teachers.

The four articles in this special issue focus on different stages of professional development of mathematics teachers and teacher education: two papers address prospective teacher education (Bartolini Bussi; Pitta-Pantazi and Christou) and two address professional development for practicing teachers (Clements and Sarama; Tirosh, Tsamir, Levenson, and Tabach). The papers are written by researchers from different countries, representing different research traditions and various theoretical frameworks. Care was taken to ensure that, altogether, the papers address the main content domains commonly associated with mathematics curricula for young children: numbers and geometry. Various cognitive, institutional, and societal issues are also addressed (e.g., attending to research on children's learning, using artifacts and signs, scaling up professional development, and assessing the results of professional development). This introduction attempts to provide a preliminary guide for the reader of this issue. It offers a brief synopsis of each article including how the various articles relate to each other and some closing remarks including some thoughts for future research.

Perhaps the main concern of most early childhood educators is developing children's knowledge in the domain of numbers. Within this domain, the guidelines and curricula of various countries mention several goals for children to reach by the time they enter first grade. For instance, in the U. S., the Standards for School Mathematics (National Council of Teachers of Mathematics 2000, p. 77) states: “... it is absolutely essential that students develop a solid understanding of the base-ten numeration system in prekindergarten through grade 2 . They must recognize that the word ten may represent a single entity (1 ten) or ten separate units (10 ones) and that these representations are interchangeable". This content goal, and more specifically, how to educate prospective teachers of young children so that they may effectively teach this important aspect of number knowledge, is dealt with in the article by Bartolini Bussi. There, Bartolini Bussi describes the Artefact, 
Instrument, Semiotic Mediator (AISM) theoretical framework. This framework guides the activities in a workshop for pre-primary and primary teachers, where the use of artifacts in learning place value is tackled. Results of the workshop, as reported by Bartolini Bussi, as well as other faculty members and participating prospective teachers, were positive. Participants not only constructed the semiotic potential of the artefacts but, equally important, reported a positive attitude towards learning mathematics.

Another goal within the domain of number concepts is being able to compare the number of objects in two sets, including the empty set as well as being able to divide one set of objects into equivalent sets, i.e. sets with an equal number of objects. These goals incorporate important skills such as counting, one-to-one correspondence, and fair-sharing (Gelman 1993; Nunez and Bryan 1996). They lay the foundation for composing and decomposing numbers, addition and subtraction, as well as multiplication and division (Steffe 2004). This content goal is the focus of the article by Tirosh, Tsamir, Levenson, and Tabach. In this article, they describe four lessons of a professional development program for practicing preschool teachers, revolving around the concept of equivalent sets. They illustrate how enhancing knowledge may filter down to teachers' practice which in turn may result in increased knowledge among children. They emphasize that teaching mathematics, including mathematics in early childhood, should not only include mathematical content but also mathematical processes. Thus, in their professional development lessons, and later on when they evaluate children's knowledge of equivalent sets, they also relate to the issue of multiple methods and multiple solutions.

During the preschool years, children are also developing and refining their spatial and geometric thinking (Clements et al. 1999). Thus it is not surprising that a second major content domain mentioned in preschool mathematics curricula is geometry and spatial reasoning. Within the domain of geometry, several curricula (e.g. Israel national mathematics preschool curriculum (INMPC) 2008; NCTM 2006) recommend that kindergarten children learn to identify two-dimensional and three-dimensional shapes presented in a variety of ways. Yet, of all mathematics topics, geometry was the one prospective teachers claimed to have learned the least about and believed they were least prepared to teach (Jones et al. 2002). In their article, Clements and Sarama review research on professional development, and describe a series of research and development projects based on this body of knowledge. Significantly, they discuss how a successful approach may be scaled up across a large number of diverse populations and contexts, avoiding the dilution and pollution that usually plagues such efforts. As did Tirosh, Tsamir, Levenson, and Tabach, results of the professional development program were also measured by assessing the knowledge of children who learned with participating teachers.

As many teacher educators and researchers will attest, it is imperative to investigate teachers' knowledge, including how different constructs might be related to form schema, in order to adequately plan professional development. This is the focus of Pitta-Pantazi and Christou's study. In their paper, they report on a theoretical model of proportional reasoning and how it is amended and empirically verified with prospective kindergarten teachers. The significance of this study lies not only in the model and its use in investigating prospective teachers' knowledge. It deals with a context, proportional reasoning, which although one might think is not associated with young children, has its roots in many early childhood concepts, such as sharing and comparing and part-whole comparison. This study emphasizes how important it is when educating early childhood teachers to have them look beyond the immediate goal. Early childhood mathematics instruction should take into consideration that what is being learned at this early age will be reflected in children's later understanding of major mathematical concepts. 
In bringing this introduction to a close, we cannot but help point out the many important issues that are not discussed in this issue. To begin with, number concepts and geometry for young children include much more than what is dealt with in this issue. Early childhood teachers' knowledge and conceptions of number operations, measurement, and patterns, to name but a few, need to be explored. In addition, the articles in this issue relate to promoting and investigating early childhood teachers' mathematics knowledge, both subject-matter knowledge and pedagogical-content knowledge. However, none of the papers touch upon early childhood teachers' beliefs and attitudes regarding mathematics and the teaching of mathematics, as well as other affective issues such as self-efficacy. This issue is entitled "Windows to Early Childhood Mathematics Teacher Education". We invite you to look inside, explore some of the issues raised, and raise some questions of your own. We hope that the windows we provide in this issue will stimulate additional and necessary research in the field early childhood mathematics teacher education.

\section{References}

Ball, D., Thames, M., \& Phelps, G. (2008). Content knowledge for teaching. Journal of Teacher Education, 59(5), 389-407.

Bowman, B. T., Donovan, M. S., Burns, M. S., et al. (2001). Eager to learn: Educating our preschoolers. Washington, DC: National Academy Press.

Clements, D. H., \& Sarama, J. (2007). Early childhood mathematics learning. In F. K. Lester (Ed.), Second handbook of research on mathematics teaching and learning (461-556). Charlotte, NC: Information Age Publishing.

Clements, D. H., Swaminathan, S., Hannibal, M. A. Z., \& Sarama, J. (1999). Young children's concepts of shape. Journal for Research in Mathematics Education, 30, 192-212.

Gelman, R. (1993). A rational-constructivist account of early learning about numbers and objects. In D. Medin (Ed.), Learning and Motivation (pp. 61-96). New York: Academic Press.

Israel national mathematics preschool curriculum (INMPC) (2008). Retrieved April 7, 2010, from http://meyda.education.gov.il/files/Tochniyot_Limudim/KdamYesodi/Math1.pdf.

Jimerson, S., Egelnad, B., \& Teo, A. (1999). A longitudinal study of achievement trajectories: Factors associated with change. Journal for Educational Psychology, 91, 116-126.

Jones, K., Mooney, C., \& Harries, T. (2002). Trainee primary teachers' knowledge of geometry for teaching. Proceedings of the British Society for Research into Learning Mathematics, 22(2), 95-100.

Krajewski, K. (2005). Prediction of mathematics (dis-)abilities in primary school: A 4-year German longitudinal study from Kindergarten to grade 4. Atlanta, GA: Paper presented at the Biennial Meeting of the Society for Research in Child Development.

National Association for the Education of Young Children and National Council of Teachers of Mathematics, (2002). Position statement. Early childhood mathematics: Promoting good beginnings. Available: www.naeyc.org/resources/position_statements/psmath.htm.

National Council of Teachers of Mathematics. (2000). Principles and standards for school mathematics. Reston, VA: NCTM.

National Council of Teachers of Mathematics. (2006). Curriculum focal points for kindergarten through grade 8 mathematics. Reston, VA: NCTM.

Nunez, T., \& Bryan, P. (1996). Children Doing Mathematics. Oxford: Blackwell.

Sarama, J., \& DiBiase, A. (2004). The professional development challenge in preschool mathematics. In D. H. Clements, J. Sarama, \& A. DiBiase (Eds.), Engaging young children in mathematics: Standards for early childhood mathematics education (pp. 415-447). Mahwah, NJ: Lawrence Erlbaum.

Shulman, L. (1986). Those who understand: Knowledge growth in teaching. Educational Researcher, 15(2), 4-14.

Steffe, L. P. (2004). PSSM from a constructivist perspective. In D. H. Clements \& J. Sarama (Eds.), Engaging young children in mathematics (pp. 221-252). Mahwah, NJ: Lawrence Erlbaum Associates. 